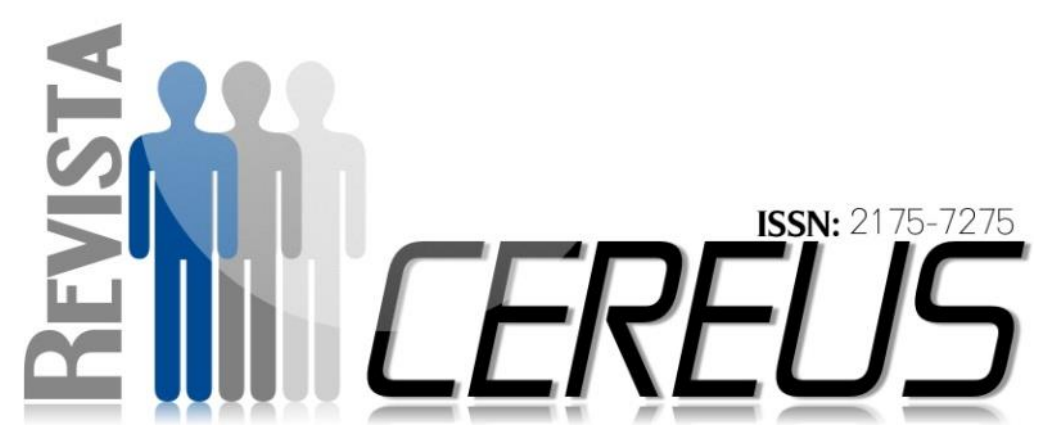

\title{
PERFIL DE RESISTÊNCIA BACTERIANA EM FÔMITES DE UTI EM HOSPITAL PÚBLICO DO ESTADO DO TOCANTINS
}

\author{
ARAUJO, Michelly Queren ${ }^{1}$ \\ CARVALHAES, Rafael Paiva ${ }^{1}$ \\ FARIA, Samara Oliveira ${ }^{1}$ \\ MARINHO, Maressa Ferreira ${ }^{1}$ \\ SANTOS, Fernanda Martins dos ${ }^{1}$ \\ SANTOS, Tania Greicy Quirino Alves dos ${ }^{2}$ \\ POLETTO, Karine Queiroz ${ }^{3}$ \\ BESSA, Nelita Gonçalves Faria ${ }^{4}$
}

\section{RESUMO}

Introdução: As infecções bacterianas hospitalares em Unidades de Terapia Intensiva (UTIs) ainda são motivos de grande preocupação devido ao elevado índice de mortalidade. Trata-se de um ambiente hospitalar com possibilidades de disseminação de bactérias, muitas vezes, resistentes aos antibióticos e presentes em fômites. Objetivo: Identificar as bactérias presentes em objetos inanimados da UTI do Hospital Regional de Gurupi -TO e traçar o perfil de resistência bacteriana a antimicrobianos. Metodologia: Realizou-se um estudo transversal. Foram colhidas amostras

${ }^{1}$ Centro Universitário Unirg. Graduandos do Curso de Medicina do Centro Universitário Unirg. E mail para correspondência: michelly queren@hotmail.com

${ }^{2}$ Graduanda do Curso de Medicina do Centro Universitário Unirg. Enfermeira da Unidade de Terapia Intensiva do Hospital Regional Público de Gurupi-TO

${ }^{3}$ Biomédica. Mestre em Medicina Tropical/Microbiologia. Professora Adjunto III do Centro Universitário Unirg. Gurupi-TO.

${ }^{4}$ Eng. Agrônoma. Doutora em Biologia e Ecologia Tropical. Professora efetiva de Pesquisa em Saúde, curso de Medicina do Centro Universitário Unirg, Gurupi-TO. 
em cinco superfícies de fômites dos leitos da UTI, sendo cultivadas em meios de cultura e os microrganismos identificados de acordo com as provas bioquímicas de catalase e coagulase. Os microrganismos identificados foram submetidos ao antibiograma pelo método de difusão de discos. A resistência bacteriana foi verificada pela formação ou não de halos ao redor dos discos antibiogramas, medindoos quando presentes. Resultados: Dos 5 fômites coletados, resultaram em 50 amostras, dentre as quais foram isoladas 37 colônias. Das amostras onde houve crescimento bacteriano, 36 eram Gram positivas e 1 Gram negativa. Não houve crescimento de Streptococcus sp, sendo 28 amostras de Staphylococcus aureus e 5 de Staphylococcus coagulase negativas. Destas, 2 foram identificadas como Staphylococcus epidermidis. A única espécie de bactéria Gram negativa encontrada foi a Shigella sorotipos A, B e C. As bactérias isoladas foram mais resistentes ao Extrato de Siparuna Guianensis (100\%), seguida da Ceftazidima (95,23\%), Claritromicina e Gentamicina $(76,20 \%)$ e à Oxacilina (71,42\%). Conclusão: Os fômites avaliados apresentaram, na sua maioria, bactérias com potencial patogênico e de multirresistência para antibióticos de uso na Terapia Intensiva e extrato de planta medicinal sugerindo revisão de boas práticas neste ambiente.

Palavras-chave: Unidades de Terapia Intensiva. Resistência a antibióticos. Atividade antimicrobiana. Produtos naturais.

\section{BACTERIAL RESISTANCE PROFILE IN ICU FACTS IN A PUBLIC HOSPITAL OF THE STATE OF TOCANTINS}

\section{ABSTRACT}

Introduction: Bacterial infections in Intensive Care Units (ICUs) are still of great concern because of the high mortality 
rate. It is a hospital environment with possibilities of dissemination of bacteria, often resistant to antibiotics and present in fomites. Objective: To identify the bacteria present in inanimate objects of the ICU of the Regional Hospital of Gurupi City and to trace the profile of bacterial resistance to antimicrobials. Methods: A cross-sectional study was carried out. Samples were collected on five labial surfaces of the ICU beds and cultured in culture media and the microorganisms identified according to the biochemical tests of catalase and coagulase. The identified microorganisms were submitted to the antibiogram by disc diffusion method. Bacterial resistance was verified by the formation of halos around the antibiogram disks, measuring them when present. Results: Of the 5 samples collected, 50 samples were obtained, of which 37 colonies were isolated. Of the samples with bacterial growth, 36 were Gram positive and $1 \mathrm{Gram}$ negative. There was no growth of Streptococcus sp, being 28 samples of Staphylococcus aureus and 5 of Staphylococcus negative coagulase. Of these, 2 were identified as Staphylococcus epidermidis. The isolates were more resistant to the Siparuna guianensis extract (100\%), followed by Ceftazidime (95.23\%), Clarithromycin and Gentamicin (76, 20\%) and to Oxacillin (71.42\%). Conclusion: Most of the samples studied showed bacteria with pathogenic potential and multiresistance for antibiotics used in intensive care and medicinal plant extract suggesting a review of good practices in this environment.

Key Words: Intensive care Units. Drug resistance, Microbial. Activity antimicrobian. Natural products. 


\section{INTRODUÇÃO}

O início do uso clínico dos antimicrobianos evidenciou

a capacidade dos microrganismos de se tornarem resistentes (VERONESI, 2015). A susceptibilidade bacteriana aos antibióticos, que é elevada à primeira exposição, tende a reduzir após exposições subsequentes. Essa resistência é conferida à bactéria por fatores genéticos, como mutações, sendo transmitida à progênie por mecanismos normais de reprodução e relaciona-se ao uso indiscriminado, empírico e rotineiro de antibióticos (GRILLO, 2013). Além disso, a capacidade de se reproduzir rapidamente faz com que haja um grande número de bactérias resistentes em um curto espaço de tempo (TORTORA, 2012).

O aumento da resistência aos antibióticos é ainda mais importante em se tratando do ambiente hospitalar, pois as infecções relacionadas à assistência à saúde (IRAS) são um grave problema de saúde pública. Neste contexto, vários fatores contribuem, tanto para o surgimento de bactérias resistentes, como para a sua disseminação junto a hospedeiros suscetíveis (VERONESI, 2015).

O ambiente ocupado por pacientes colonizados e/ou infectados pode tornar-se contaminado (OLIVEIRA e DAMASCENO, 2010) e servir como reservatório de cepas patogênicas que são transmitidas por contaminação cruzada. Desta forma, superfícies inanimadas como roupas e equipamentos que cercam o paciente, estão relacionadas às infecções hospitalares (PAULA, SALGE, PALOS, 2017). Ademais, um importante meio de disseminação de patógenos são as mãos dos profissionais de saúde mesmo após melhorias nas medidas de higienização das mãos o que reafirma o ambiente como fator de risco na transmissão de microrganismos (FERREIRA et al, 2013).

Das infecções nosocomiais, mais de $20 \%$ são adquiridas nas UTI's. As infecções sangüíneas associadas ao cateter (CRBSIs), a pneumonia associada ao ventilador (VAP) e as infecções do trato urinário associadas ao cateter (CAUTIs) são as principais desse ambiente. $O$ aumento da taxa de resistência bacteriana também está associado às UTI's, sendo os principais patógenos os Enterococos resistentes 
à vancomicina (VRE), Staphylococcus aureus meticilina resistente (MRSA), $P$ seudomonas aeruginosa resistente às fluorquinolonas ou ao imipenem, Acinetobacter baumannii resistente aos carbapenens, enterobactérias resistentes as cefalosporinas de terceira geração, produtoras de betalactamase de espectro estendido (ESBL) e as Enterobactérias resistentes aos carbapenens (MARCHAIM et al., 2017)

O surgimento da resistência, principalmente do espectro amplo entre gram-negativos, causa preocupação devido à escassez das alternativas terapêuticas e, às vezes, à indisponibilidade de agente antimicrobiano efetivo (MARCHAIM et al., 2017), com necessidade de desenvolver novos medicamentos antibacterianos (SANTOS, 2014). Pesquisas com produtos naturais têm sido desenvolvidas com este foco, na perspectiva de substituição de alopáticos e a um menor custo.

Os produtos naturais têm

\section{METODOLOGIA}

Foi desenvolvido um estudo transversal, autorizado pelo Hospital Regional de Grurupi-TO (FormSus), apresentado atividades antimicrobianas em pesquisas realizadas no Brasil, com relevância do ponto de vista econômico, pela possibilidade de substituição de produtos sintéticos importados de elevado valor de mercado (KNAAK e FIUZA, 2010; SOUZA et al., 2013). A Siparuna guianensis é uma espécie medicinal cujo uso já é popularmente difundido em vários países da América do sul e Brasil, sendo potencial para fármacos e ainda pouco estudada. A fitoquímica do seu extrato bruto foliar aponta para ação antimicrobiana, possivelmente, devido aos terpenos, taninos e flavonóides (BESSA et al., 2013).

Diante do exposto o presente estudo objetivou identificar as bactérias presentes em objetos inanimados da UTI do Hospital Regional de Gurupi TO e traçar o perfil de resistência bacteriana à antimicrobianos frequentemente utilizados neste ambiente hospitalar e ao extrato foliar vegetal de espécie nativa. 
humanos (parecer $\mathrm{n}^{\circ} 1.840 .703$ ). A coleta das amostras foi realizada em novembro de 2016, durante duas semanas. A UTI estudada possui 10 leitos para pacientes adultos, porém, recebe internações de pacientes pediátricos e neonatais esporadicamente. A taxa de ocupação desses leitos em um ano é, em média, $98 \%$.

Foram incluídas nesse estudo, cinco superfícies de fômites, sendo: grades das camas, manivelas ou controles remotos, no caso de camas com este dispositivo, mesas de cabeceira, botões das bombas de infusão e botões dos ventiladores mecânicos dos leitos da UTI. A coleta foi realizada independentemente da disposição dos fômites no ambiente, bem como da faixa etária ou sexo dos pacientes neles internados, desde que fossem integrantes da UTI. Esses objetos foram escolhidos por serem frequentemente tocados, expondo a equipe de assistência à saúde e os pacientes aos microrganismos presentes.

As amostras foram colhidas ao menos em $50 \%$ da área total da superfície do fômite, usando swab e posteriormente inoculadas em meio Stuart. A coleta foi realizada em horário estipulado pelo hospital, após a limpeza de rotina, sem comunicar os trabalhadores da limpeza ou equipe de enfermagem, a fim de minimizar as mudanças em seus comportamentos. As amostras foram rapidamente levadas para análise microbiológica do material no laboratório de Microbiologia, acondicionadas em caixa de isopor. O manejo das amostras e os procedimentos de inoculação foram realizados em capela de fluxo laminar.

As amostras foram inoculadas no Ágar Mac Conkey e Ágar Manitol Salgado e incubadas por 48 horas em estufa a $35^{\circ} \mathrm{C}$. As colônias crescidas no Ágar Mac Conkey foram inoculadas no Ágar tríplice açúcar ferro, Meio MIO (motilidade, indol e ornitina), Ágar Citrato e no Ágar Fenilalanina; e incubadas na estufa a $35^{\circ} \mathrm{C}$ por 18 a 24h. Após o período de incubação, as bactérias foram identificadas de acordo com as reações bioquímicas e enzimáticas ocorridas no interior dos meios de cultura. As colônias crescidas no Ágar manitol Salgado foram identificadas através das provas de catalase e coagulase (KONEMAN et al., 2001).

As colônias gram-positivas foram identificadas pelos testes de 
produção de catalase e coagulase. As Gram-negativas foram caracterizadas pelos testes de fermentação de carboidratos, produção de indol, produção de ácidos orgânicos, utilização de citrato, motilidade, ornitina descarboxilase e produção da enzima fenilalanina-desaminase (CUSTÓDIO et al., 2009).

Os microrganismos identificados foram submetidos ao antibiograma pelo método de difusão de discos (KirbyBauer), (CLSI, 2006). Foi realizada a padronização de todos os inóculos, tocando com o auxílio de uma alça de Drigalski a placa de Ágar Mac Conkey ou Ágar Manitol Salgado contendo os microrganismos, com transferência de cada inóculo para um tubo de ensaio contendo solução salina estéril, ajustando a turbidez obtida com esta diluição à solução padrão de McFarland a 0,5 de forma a resultar aproximadamente de 1 a $2 \times 108$ $\mathrm{UFC} / \mathrm{mL}$. A semeadura das bactérias foi realizada em placas de petri de 150 $\mathrm{mm}$ contendo meio sólido MuellerHinton. Foram usados os seguintes discos de antibióticos: Vancomicina, Amicacina, Cefaclor, Ceftriaxona, Gentamicina, Amoxicilina com clavulanato, Oxacilina, Claritromicina, Ceftazidima, Linezolida, Cefalexina,
Levofloxacina,

Imipenem,

Clotrimoxazol (sulfametoxazol + trimetoprima). Ainda, foram usados discos contendo o extrato bruto foliar vegetal de negramina (Siparuna guianensis), obtido na Unidade de Apoio a Pesquisa com Produtos Naturais - UAP, seguindo metodologia descrita por Matos (2009). Todos os discos foram colocados nas placas, exercendo uma pressão mínima na deposição de cada um deles na superfície do meio. Estes discos (antibióticos comerciais e extrato da planta) distaram um dos outros em média 2,4cm (CLSI, 2006). As placas foram incubadas em posição invertida em estufa a $35^{\circ} \mathrm{C}\left( \pm 2^{\circ} \mathrm{C}\right)$ e avaliadas. $\mathrm{O}$ diâmetro do halo foi medido em milímetros ( $\mathrm{mm})$, usando um halômetro graduado (CLSI, 2006).

Os dados foram ordenados em banco de dados com o auxílio do programa Microsoft Excel 2013, sendo a análise feita a partir da avaliação da positividade bacteriana encontrada em cada fômite, com identificação das bactérias e respectivo perfil de resistência bacteriana frente aos antimicrobianos utilizados, sendo os resultados apresentados em tabelas e gráficos. 


\section{RESULTADOS}

Dos 5 fômites coletados em 10 leitos da UTI no ano de 2016, totalizando 50 amostras, em apenas 14 delas não houve crescimento de colônias. Das amostras nas quais houve crescimento bacteriano foram isolados 37 microrganismos, dos quais 36 (97,29\%) eram Gram positivos e 1 $(2,71 \%)$ Gram negativo.

Das amostras de Gram positivos, foram identificadas 28 $(75,7 \%) \quad$ contaminadas por Staphylococcus aureus e 5 contaminadas por Staphylococcus coagulase negativo. Em apenas três Staphylococcus coagulase negativo o crescimento foi suficiente para a realização do teste de identificação da espécie bacteriana, sendo possível a identificação de dois destes como Staphylococcus epidermidis através do teste com Novobiocina (tabela 1).

Somente uma amostra, colhida da grade da maca do leito 2, foi identificada como microrganismo Gram negativo. Verificou-se através dos estudos bioquímicos, como sendo Shigella sorotipos A, B e C.

A superfície em que houve maior crescimento de $S$. aureus multiresistente foi de grades das camas, $80 \%$ (8/10), sendo que também nesta superfície foram encontradas cepas de $S$. epidermidis e Shiguella sp. Esse resultado foi semelhante ao obtido por Sales (2014), onde as grades das camas foram uma das superfícies mais contaminadas juntamente com os respiradores mecânicos, as bombas de infusão, os monitores cardíacos e os estetoscópios. Esse achado pode ser um reflexo do contato frequente tanto dos profissionais de saúde como de visitantes e do próprio paciente com as grades da cama, além da não higienização adequada das mãos dos contactantes e da própria superfície, tornando-a uma das mais contaminadas do peri-leito.

As outras superfícies analisadas (manivelas/ controles remotos, mesas de cabeceira, botões das bombas de infusão, botões dos ventiladores mecânicos) apresentaram-se igualmente contaminados, com crescimento bacteriano de $60 \%(6 / 10)$. 
Tabela 1. Identificação dos microrganismos Gram positivos e relação de crescimento bacteriano, de acordo com fômites e leitos de UTI, Hospital Regional de Gurupi-TO.

\begin{tabular}{|c|c|c|c|c|c|}
\hline $\begin{array}{l}\text { Fômites } \\
\text { Leitos }\end{array}$ & $\begin{array}{l}\text { Grades } \\
\text { das } \\
\text { camas }\end{array}$ & $\begin{array}{c}\text { Manivelas } \\
\text { ou controle } \\
\text { remotos }\end{array}$ & $\begin{array}{l}\text { Mesas de } \\
\text { cabeceira }\end{array}$ & $\begin{array}{c}\text { Botões das } \\
\text { Bombas de } \\
\text { infusão }\end{array}$ & $\begin{array}{c}\text { Botões dos } \\
\text { ventiladores } \\
\text { mecânicos }\end{array}$ \\
\hline 1 & $\begin{array}{l}\mathrm{Ca}+ \\
\mathrm{Co}+\end{array}$ & $\begin{array}{l}\mathrm{Ca}+ \\
\mathrm{Co}+\end{array}$ & - & * & - \\
\hline 2 & $\begin{array}{l}\mathrm{Ca}+ \\
\mathrm{Co}-\end{array}$ & - & $\begin{array}{l}\mathrm{Ca}+ \\
\mathrm{Co}+\end{array}$ & - & - \\
\hline 3 & $\begin{array}{l}\mathrm{Ca}+ \\
\mathrm{Co}+\end{array}$ & * & * & $\begin{array}{l}\mathrm{Ca}+ \\
\mathrm{Co}+\end{array}$ & $\begin{array}{l}\mathrm{Ca}+ \\
\mathrm{Co}-\end{array}$ \\
\hline 4 & $\begin{array}{l}\mathrm{Ca}+ \\
\mathrm{Co}+\end{array}$ & $\begin{array}{l}\mathrm{Ca}+ \\
\mathrm{Co}+\end{array}$ & - & - & $\begin{array}{l}\mathrm{Ca}+ \\
\mathrm{Co}+\end{array}$ \\
\hline 5 & $\begin{array}{l}\mathrm{Ca}+ \\
\mathrm{Co}+\end{array}$ & $\begin{array}{l}\mathrm{Ca}+ \\
\mathrm{Co}+\end{array}$ & $\begin{array}{l}\mathrm{Ca}+ \\
\mathrm{Co}+\end{array}$ & $\begin{array}{l}\mathrm{Ca}+ \\
\mathrm{Co}+\end{array}$ & $\begin{array}{l}\mathrm{Ca}+ \\
\mathrm{Co}-\end{array}$ \\
\hline 6 & $\begin{array}{l}\mathrm{Ca}+ \\
\mathrm{Co}+\end{array}$ & $\begin{array}{l}\mathrm{Ca}+ \\
\mathrm{Co}+\end{array}$ & - & $\begin{array}{l}\mathrm{Ca}+ \\
\mathrm{Co}+\end{array}$ & $\begin{array}{l}\mathrm{Ca}+ \\
\mathrm{Co}+\end{array}$ \\
\hline 7 & - & $\begin{array}{l}\mathrm{Ca}+ \\
\mathrm{Co}-\end{array}$ & $\begin{array}{l}\mathrm{Ca}+ \\
\mathrm{Co}+\end{array}$ & $\begin{array}{l}\mathrm{Ca}+ \\
\mathrm{Co}+\end{array}$ & - \\
\hline 8 & $\begin{array}{l}\mathrm{Ca}+ \\
\mathrm{Co}+\end{array}$ & & $\begin{array}{l}\mathrm{Ca}+ \\
\mathrm{Co}+\end{array}$ & $\begin{array}{l}\mathrm{Ca}+ \\
\mathrm{Co}+\end{array}$ & - \\
\hline 9 & $\begin{array}{l}\mathrm{Ca}+ \\
\mathrm{Co}+\end{array}$ & $\begin{array}{l}\mathrm{Ca}+ \\
\mathrm{Co}+\end{array}$ & $\begin{array}{l}\mathrm{Ca}+ \\
\mathrm{Co}+\end{array}$ & $\begin{array}{l}\mathrm{Ca}+ \\
\mathrm{Co}+\end{array}$ & $\begin{array}{l}\mathrm{Ca}+ \\
\mathrm{Co}-\end{array}$ \\
\hline 10 & $\begin{array}{l}\mathrm{Ca}+ \\
\mathrm{Co}+\end{array}$ & & $\begin{array}{l}\mathrm{Ca}+ \\
\mathrm{Co}+\end{array}$ & - & $\begin{array}{l}\mathrm{Ca}+ \\
\mathrm{Co}+\end{array}$ \\
\hline
\end{tabular}

$\mathrm{Ca}+$ : catalase positiva (Staphylococcus $\mathrm{sp}$.); $\mathrm{Ca}$ - : catalase negativa (Streptococcus $\mathrm{sp}$.)

$\mathrm{Co}+$ : coagulase positiva (Staphylococcus aureus); Co - : coagulase negativo (Staphylococcus coagulase negativo); - : não houve crescimento bacteriano; *: amostra insuficiente para o teste.

O crescimento microbiano predominante de Staphylococcus aureus multirresistente nas superfícies dos equipamentos estudados mostra a relevância deste patógeno no contexto hospitalar, sendo responsável por um variado número de manifestações clínicas. São frequentemente encontrados na pele e nas fossas nasais de pessoas saudáveis. Entretanto, podem provocar tanto doenças benignas como infecções de pele (espinhas, furúnculos e celulites), quanto infecções graves como pneumonia, meningite, endocardite, síndrome do choque tóxico, septicemia (HOLLAND e FOWLER, 2017). Esse microrganismo coloniza cerca de $30 \%$ das pessoas, sendo a principal causa de bacteremia, endocardite infeciosa (IE), além de infecção osteoarticular, de pele e tecidos moles, infecção 
pleuropulmonar e relacionadas a dispositivos (TONG, 2015).

Os estafilococos coagulase negativos (ECN) são os mais presentes na microbiota normal da pele e estão sendo cada vez mais relacionados a infecções importantes como bacteremia e endocardite (TUFARIELLO e LOWY, 2017). Dentre eles, o Staphylococcus epidermidis, maior espécie dos ECN, é uma causa frequente de sepse, principalmente em neonatos (OTTO, 2017) e é frequentemente causador de infecções relacionadas a dispositivos e próteses. Desta forma, pacientes com próteses, marcapassos, cateteres intravasculares e aqueles imunocomprometidos são considerados de risco para infecções por essa espécie (TUFARIELLO e LOWY, 2017).

A Shigella sp tem a via fecal-oral como principal forma de transmissão, causa infecção benigna com quadro auto-limitado de dor abdominal e cólica, diarréia com sangue, pus ou muco, febre, vômitos e tenesmo, apresentando as seguintes projeções para ambientes de UTI: presença de infecção grave, com febre alta, podendo estar associada com convulsões em crianças menores de 2 anos de idade, sendo algumas cepas responsáveis por uma taxa de letalidade de 10 a $15 \%$ e produzem uma enterotoxina tipo Shiga podendo causar a síndrome hemolítico-urêmica e artrite reativa; em idosos e imunocomprometidos, perfil presente nos pacientes de UTI, a infecção pode ocorrer de forma mais expressiva, uma vez que são mais susceptíveis (SÃO PAULO, 2013).

Em relação aos testes antibiogramas, das 28 amostras de Staphylococcus aureus, 9 tiveram amostra insuficiente para realização do teste. Desta forma, realizou-se o teste em 19 amostras de $S$. aureus, 2 amostras de $S$. epidermidis e 1 amostra de Shiguella sp.

A tabela 2 apresenta o perfil de sensibilidade e resistência das bactérias gram positivas aos antimicrobianos testados

Diante das análises dos dados obtidos observou-se que ocorreu maior sensibilidade das cepas à Vancomicina e à Linezolida (100\%), seguidas da Amicacina (90,47\%), Amoxicilina com clavulanato $(85,71 \%)$, Cefalexina (61, $90 \%$ ) e Cefaclor (52,38\%).

Os antimicrobianos que apresentaram maior percentual de resistência foram 0 Extrato de 
negramina (100\%), Ceftazidima (95,23\%), Claritromicina e Gentamicina, que obtiveram as mesmas porcentagens de resistência $(76,20 \%)$ e Oxacilina $(71,42 \%)$.

Das 2 cepas de $S$. epidermidis avaliadas, todas (100\%) foram resistentes à Gentamicina, à Ceftazidima e ao Extrato de negramina. Em contrapartida, todas (100\%) foram sensíveis à Vancomicina, Amicacina, Cefaclor, Cefalexina, Amicacina e à Linezolida. Sendo que $50 \%$ foram resistentes à Oxacilina, à claritromicina e à Ceftriaxona.

A espécie de Shigella sp identificada apresentou resistência aos seguintes antibióticos: Gentamicina, Ceftazidima, Sulfametoxazol + Trimetropima, Cefaclor, Amoxicilina com Clavulanato, Cefalexina e Claritromicina. Obteve, também, resistência ao Extrato do vegetal $S$. guianensis, assim como todas as outras bactérias testadas.

Em estudo realizado por Carvalho et al. (2015) em uma UTI de hospital público no município de Terezina - PI, foi observado resultado semelhante quanto a resistência bacteriana. Nele não foram encontradas cepas resistentes à vancomicina ou à Linezolida, e os índices de resistência à Amicacina também foram baixos (26,3\%). A maioria das bactérias foram resistentes à ceftriaxona $(96,6 \%)$, à oxacilina (100\%), à gentamicina $(71,2 \%)$ e à Ceftazidima (92,3\%), assim como no presente estudo.

O uso incorreto de antibióticos, principalmente o uso em excesso, tem sido considerado um dos fatores mais importantes para o problema da resistência microbiana, que já é tido como um problema de saúde pública global. Considerando as cepas Grampositivas, sabe-se que as espécies $S$. aureus e Enterococcus são as que apresentam maiores taxas de resistência as antibióticos. Em relação ao $S$. aureus, iniciou-se o uso da meticilina/oxacilina após estes se mostrarem resistentes às penicilinas. Entretanto, pouco tempo depois, cepas de $S$. aureus resistentes à meticilina (MRSA) começaram a ser isoladas. Hoje há uma prevalência que varia de 1\% (na Holanda) até 50\% (em países da América e Europa) (LOUREIRO et al., 2016). Nesse estudo, das 19 cepas de S. aureus isoladas, $13(68,42 \%)$ foram resistentes à oxacilina/meticilina.

A maioria dos antibióticos tiveram pelo menos uma bactéria resistente ao efeito antimicrobiano, 
porém não houveram cepas resistentes a Vancomicina e a Linezolida. Foi constatada alta resistência bacteriana frente aos antimicrobianos ceftazidima, claritromicina, oxacilina e gentamicina, com porcentagem acima de $50 \%$ das amostras. Isso indica que a baixa eficácia desses fármacos deve ser considerada durante a escolha da melhor terapêutica frente às infecções na UTI, a fim de se evitar atrasos no tratamento com uma medicação mais adequada e na obtenção de melhora clínica dos pacientes. A amicacina, amoxicilina com clavulanato, cefalexina, cefaclor, e ceftriaxona apresentaram uma resistência menor que $50 \%$.

Um dos fatores limitantes deste estudo refere-se, possivelmente, em relação ao método usado com o extrato bruto vegetal da negramina, sem efeito antimicrobiano no presente estudo com resistência em 100\% das amostras testadas, visto a já comprovada ação antimicrobiana em estudos anteriores frente a algumas bactérias presentes em ambiente hospitalar, porém, com diluições em diferentes concentrações e respectivas medições da inibição do crescimento bacteriano mínimo. Outro fator a ser destacado refere-se a eficiência amostral, que poderá em estudos posteriores, ser maximizada mediante a coleta em duplicata ou mesmo que o tempo de contato do coletor junto ao fômite seja maior, aumentando as possibilidades da obtenção de amostras suficientes para - crescimento bacteriano e consequente realização dos testes. Entretanto, há de se ressaltar que o não crescimento bacteriano suficiente para replicações pode estar relacionado à menor contaminação de algumas superfícies em detrimento de outras, não havendo relação com o método utilizado na coleta. Contudo, a metodologia utilizada nesse estudo foi suficiente para constatar que o perfil de resistência bacteriana observado a partir dos testes antimicrobianos indica a existência de bactérias multirresistentes na UTI do HRPG. 
Tabela 2. Susceptibilidade das bactérias Gram positivas aos antibióticos convencionais de uso em UTI hospitalar do HRG e ao Extrato vegetal de Negramina.

\begin{tabular}{|c|c|c|c|c|c|c|}
\hline \multirow{3}{*}{ Susceptibilidade } & \multicolumn{6}{|c|}{ Amostras } \\
\hline & \multicolumn{2}{|c|}{ Sensível } & \multicolumn{2}{|c|}{ Intermediário } & \multicolumn{2}{|c|}{ Resistente } \\
\hline & № & $\%$ & № & $\%$ & № & $\%$ \\
\hline $\begin{array}{c}\text { Antibióticos } \\
\text { Vancomicina } 30 \mathrm{mcg}\end{array}$ & 21 & $100 \%$ & 0 & $0,00 \%$ & 0 & $0,00 \%$ \\
\hline Linezolida $30 \mathrm{mcg}$ & 21 & $100 \%$ & 0 & $0,00 \%$ & 0 & $0,00 \%$ \\
\hline Amicacina $30 \mathrm{mcg}$ & 19 & $90,47 \%$ & 1 & $4,77 \%$ & 1 & $4,77 \%$ \\
\hline $\begin{array}{l}\text { Amoxicilina com } \\
\text { clavulanato } 30 \mathrm{mcg}\end{array}$ & 18 & $85,71 \%$ & 0 & $0,00 \%$ & 3 & $14,28 \%$ \\
\hline Cefalexina $30 \mathrm{mcg}$ & 13 & $61,90 \%$ & 1 & $4,77 \%$ & 7 & $33,33 \%$ \\
\hline Cefaclor $30 \mathrm{mcg}$ & 11 & $52,38 \%$ & 0 & $0,00 \%$ & 10 & $47,61 \%$ \\
\hline Ceftriaxona $30 \mathrm{mcg}$ & 8 & $38,10 \%$ & 6 & $28,57 \%$ & 7 & $33,33 \%$ \\
\hline Gentamicina $10 \mathrm{mcg}$ & 5 & $23,80 \%$ & 0 & $0,00 \%$ & 16 & $76,20 \%$ \\
\hline Oxacilina $1 \mathrm{mcg}$ & 4 & $19,04 \%$ & 2 & $9,52 \%$ & 15 & $71,42 \%$ \\
\hline Claritromicina $15 \mathrm{mcg}$ & 4 & $19,04 \%$ & 1 & $4,77 \%$ & 16 & $76,20 \%$ \\
\hline Ceftazidima $30 \mathrm{mcg}$ & 1 & $4,77 \%$ & 0 & $0,00 \%$ & 20 & $95,23 \%$ \\
\hline Extrato de Negramina & 0 & $0,00 \%$ & 0 & $0,00 \%$ & 21 & $100 \%$ \\
\hline
\end{tabular}

№: Número de amostras sensíveis, intermediárias ou resistentes.

\section{CONSIDERAÇÕES FINAIS}

O presente estudo permitiu verificar que a UTI do Hospital Regional de Gurupi -TO apresenta superfícies de fômites contaminadas, sendo mais comprometidas as grades das camas (80\%). O principal microrganismo encontrado foi Staphylococcus aureus (75,67\%), Gram positiva, seguido de Staphylococcus epidermidis $(5,4 \%)$ e da Gram negativa Shiguella sp. $(2,71 \%)$, isolada das grades da cama de um leito. Houve maior prevalência de bactérias Gram positivas na maior parte das amostras, representadas pelos S. aureus e S. epidermidis. Todas as cepas encontradas foram resistentes ao Extrato de negramina, sendo $95,23 \%$ resistentes à Ceftazidima, $76,20 \%$ à Claritromicina e à Gentamicina e $71,42 \%$ à Oxacilina. As bactérias isoladas dos fômites analisados apresentaram maior sensibilidade à Vancomicina a à Linezolida (100\%), seguidas da Amicacina (90,47\%), Amoxicilina com Clavulanato $(85,71 \%)$, Cefalexina (61, $90 \%)$ e Cefaclor (52,38\%). 
Sugere-se que sejam intensificadas as práticas de limpeza com maior orientação junto aos próprios agentes deste serviço, visto serem também potenciais veiculadores de microrganismos neste ambiente. Ainda, que ações educativas e instrucionais sejam revisadas e/ou fortalecidas junto a equipe multidisciplinar que realiza atividades laborais na UTI do HRPG, bem como sejam intensificadas as práticas de orientação junto aos visitantes, quando permitidos. Tais medidas poderão minimizar o problema recorrente das infecções bacterianas em UTI hospitalar.

\section{REFERÊNCIAS}

BESSA, N.G.F. et al. Prospecção fitoquímica preliminar de plantas do cerrado de uso popular medicinal pela comunidade rural do Assentamento Vale Verde, Tocantins. Revista Brasileira de Plantas Medicinais, n.4, p. 692-707, 2013.

CARVALHO, Magno Rodrigues de et al. Incidência de bactérias multirresistentes em uma unidade de terapia intensiva. Revista Interdisciplinar. Piauí, n. 2, v.8, abr. mai. jun. 2015, p. 75-85.

CLINICAL AND LABORATORY STANDARDS INSTITUTE (CLSI). Performance Standards for Antimicrobial Disk Susceptibility Tests. Approved Standard-Ninth Edition. Clinical and Laboratory Standards Institute document M2-A9. Wayne/Pennsylvania, USA. Janeiro, 2006. v.26, n.1. p35. http://demo.nextlab.ir/getattachment/27407437-3d73-4048-8239-

81857d68cf3d/CLSI-M2-A9.aspx

CUSTODIO, Janaina et al. Avaliação microbiológica das mãos de profissionais da saúde de um hospital particular de Itumbiara, Goiás, Brasil. Revista de ciências Médicas. Campinas, v.18, n.1, jan/fev, 2009, p.7-11.

FERREIRA, Adriano Menis et al. Superfícies do ambiente hospitalar: um possível reservatório de micro-organismos subestimado? Revisão integrativa. Revista de Enfermagem. Recife, vol. 7, p. 4171-4182, maio 2013.

GRILLO, Vinicius Tadeu Ramos da Silva et al. Incidência bacteriana e perfil de resistência a antimicrobianos em pacientes pediátricos de um hospital público de Rondônia, Brasil. Revista de Ciências Farmacêuticas Básica e Aplicada. Porto Velho, vol. 34, núm. 1, p. 117-123, 2013. 
HOLLAND, Thomas; FOWLER, Vance G. Manifestações clínicas da infecção por Staphylococcus aureus em adultos. Up To Date. Junho, 2017. Disponível em: < https://www.uptodate.com/contents/clinical-manifestations-of-staphylococcus-aureusinfection-inadults?source=search_result\&search=staphylococcus $\% 20$ aureus\&selectedTitle=3 1 $50>$ Acesso em 30/07/2017.

KNAAK, N.; FIUZA, L.M. Potential of essential plant oils to control insects and microorganisms. Neotropical Biology and Conservation, n.2, p.120-132, 2010.

KONEMAN, Elmer W; et al. Diagnóstico microbiológico: Texto e atlas colorido.

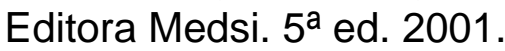

LOUREIRO, Rui João et al. O uso de antibióticos e as resistências bacterianas: breves notas sobre a sua evolução. Revista Portuguesa de Saúde Pública. Lisboa, Vol. 34, núm. 1, p. 77-84, 2016.

MARCHAIM, Dror; KAYE, Keith. Infecções e resistência antimicrobiana na unidade de terapia intensiva: epidemiologia e prevenção. Up To Date. Junho, 2017. Disponível em: https://www.uptodate.com/contents/infections-and-antimicrobialresistance-in-the-intensive-care-unit-epidemiology-and-

prevention?source=search_result\&search=infec\%C3\%A7\%C3\%B5es\%20em\%20icu \&selectedTitle=1 150 > Acesso em 30/07/2017.

MATOS, Francisco José Abreu de. Introdução a fitoquimica experimental. 3. ed. Fortaleza: edições UFC, p.143, 2009.

OLIVEIRA, Adriana Cristina de; DAMASCENO, Quésia Souza. Superfícies do ambiente hospitalar como possíveis reservatórios de bactérias resistentes: uma revisão. Revista da Escola de Enfermagem da USP. São Paulo, n 4, vol 44, Dezembro 2010, p. 118-23.

OTTO, Michael. Staphylococcus epidermidis: a major player in bacterial sepsis? Future Microbiology. Julho, 2017. Disponível em: < https://www.futuremedicine.com/doi/pdf/10.2217/fmb-2017-0143> Acesso em: 30/07/2017.

PAULA, Angélica Oliveira; SALGE, Ana Karina Marques; PALOS, Marinésia Aparecida Prado. Infecções relacionadas à assistência em saúde em unidades de terapia intensiva neonatal: uma revisão integrativa. Revista Eletrónica Trimestral de Enfermería. Janeiro, 2017.

SANTOS, Cristina D'Urso de Souza Mendes. Visão de futuro para produção de antibióticos: tendências de pesquisa, desenvolvimento e inovação. 2014. 216 f. Tese (Doutorado em Tecnologia de Processos Químicos e Bioquímicos) - Escola de Química, Universidade Federal do Rio de Janeiro. Rio de Janeiro 2014. 
SALES, Vanessa Maria et al. Análise microbiológica de superfícies inanimadas de uma Unidade de Terapia Intensiva e a segurança do paciente. Revista de Enfermagem Referência. Série IV, núm. 3. Nov/Dez, 2014.

SECRETARIA DE ESTADO DA SAÚDE DE SÃO PAULO. Doenças transmitidas por água e alimentos: Shigella spp/Shigeloses. Informe - net DTA. 2013. Disponpivel em: < $\quad$ http://www.saude.sp.gov.br/resources/cve-centro-de-vigilanciaepidemiologica/areas-de-vigilancia/doencas-transmitidas-por-agua-ealimentos/doc/bacterias/201315shigella_revisado.pdf>

SOUZA, J.N.P. et al. Bioprospecção das atividades antioxidante e antimicrobiana de espécies vegetais medicinais coletadas em Ouro Preto-MG. Revista Eletrônica de Farmácia. v. x (1), p. $01-15.2013$

TONG, Steven Y. C et al. Staphylococcus aureus Infections: Epidemiology, Pathophysiology, Clinical Manifestations, and Management. Clinical Microbiology Review, Vol. 28, Núm. 3, Julho, 2015.

TORTORA, Gerard J.; FUNKE, Berdell R.; CASE, Christine L.; Microbiologia. Ed 10. Porto Alegre: Artmed, 2012.

TUFARIELLO, Joann M.; LOWY, Franklin D. Epidemiologia, microbiologia e patogênese de estafilococos coagulase-negativos. Up To Date. Junho, 2017. Disponível em: < https://www.uptodate.com/contents/epidemiology-microbiology-andpathogenesis-of-coagulase-negative-

staphylococci?source=search_result\&search=staphylococcus\%20epidermidis\&select edTitle $=2 \sim 150>$ Acesso em: 30/07/2017.

VERONESI, Ricardo; Focaccia, Roberto. Tratado de infectologia. 5ª Ed. São Paulo: Editora Atheneu, 2015. 